\title{
Ley № 20.066 sobre Violencia Intrafamiliar: ¿un cambio de paradigma?
}

\author{
Lidia Casas Becerra*
}

\begin{abstract}
a violencia contra la mujer representa uno de aquellos temas que sin la intervención del movimiento de mujeres y feminista desde finales de la década de los ochenta no se hubiera logrado posicionar en la agenda pública en Chile. Las movilizaciones por la democratización del país para poner fin a la dictadura de Pinochet se sumó a la demanda de agrupaciones de mujeres por democratizar el espacio familiar y erradicar la violencia contra la mujer. El advenimiento democrático fue un momento propicio para que un nuevo orden avanzara en una agenda legislativa que reconociera la violencia en la familia como una cuestión pública, lo que permitió la dictación de la primera ley sobre violencia intrafamiliar ${ }^{1}$. Las herramientas legales y vías procesales existentes antes de esta ley no habían sido eficaces. Quizá lo más paradigmático fue constatar que la vía cautelar de protección, un recurso procesal rápido y sin formalidades para la protección de la integridad física y psíquica, no fue acogido por los tribunales como "la vía idónea" para la protección de las víctimas en casos de violencia intrafamiliar. Así, los jueces rechazaban los recursos aduciendo, en ocasiones, que las "rencillas familiares" eran materias que carecían de relevancia para la jurisdicción proteccional ${ }^{2}$.
\end{abstract}

Este primer paso normativo constituyó una ley de "transición" en que se enfrentaban por primera vez distintas nociones y visiones sobre la familia en Chile. En nuestra tradición legal esta se ha erigido como una organización jerarquizada, estableciendo prerrogativas para el maridopadre y cimentada sobre la idea de legitimidad familiar dada por el vínculo matrimonial.

Si bien un lustro antes de la dictación de la Ley № 19.325 se modificó el Código Civil en materia del derecho de familia ${ }^{3}$, estableciendo que la mujer ya no obedecía al marido sino que los cónyuges se debían respeto recíproco, y morigerando el poder del marido en la administración de los bienes, hasta el día de hoy la ley considera al marido como el jefe de la familia (de la sociedad conyugal) para lo cual cuenta con una serie de privilegios ${ }^{4}$. Cuando se dictó la ley de violencia intrafamiliar no había divorcio vincular, no existía igualdad jurídica de los hijos nacidos dentro y fuera del matrimonio ni tampoco se habían regulado las relaciones de hecho.

En este contexto, la dictación de la Ley № 19.325 fue un gran avance, pues estableció que la violencia intrafamiliar era una conducta merecedora de un reproche social. Esta ley rompe con la idea tradicional
* Profesora e investigadora del Centro de Investigaciones Jurídicas de la Universidad Diego Portales.

1 Ley de Violencia Intrafamiliar № 19.325 de agosto de 1994.

2 Cabal, Luisa, Lemaitre, Julieta y Roa, Mónica, Cuerpo y Derecho. Legislación y Jurisprudencia en América Latina, Centro Legal para Derechos Reproductivos, Universidad de Los Andes y TEMIS, Bogotá, 2001, pp. 148-149.

3 La Ley № 18.802 publicada el 9 de junio de 1989.

4 Pese a los esfuerzos de modificar las normas sobre el derecho de familia, el marido se erige como el jefe de la sociedad conyugal $y$, en tanto goza de esa capacidad puede disponer libremente de los bienes muebles sociales, los bienes propios de la mujer y administrar los inmuebles con las restricciones establecidas en el artículo 1749 del Código Civil.

Este comentario, junto con el documento principal a que se refiere, están disponibles en www.anuariocdh.uchile.cl 
5 Ley № 20.066, publicada el 7 de octubre de 2005.

6 Siegel, Reva, "Regulando la violencia marital" trad. Roberto Gargarella, Derechos y Grupos desaventajados, Roberto Gargarella comp., Yale Law School, Universidad de Palermo y GEDISA Editorial, Barcelona, 1999, pp. 83-84.

7 Los estudios sobre esta materia dan cuenta de los déficits que el país muestra en la materia. Véase Casas, Lidia y Mera, Alejandra, Violencia de Género. Delitos sexuales y Reforma Procesal Chilena, Cuadernos de Análisis Jurídicos № 16, Centro de Justicia de las Américas y Universidad Diego Portales, Santiago, 2004. de la familia basada en el matrimonio e incluye expresamente en la esfera de protección a todos los miembros de la familia que vivan bajo el mismo techo, independientemente de si están unidos o no por vínculo conyugal. A fin de contextualizar los cambios que introduce la Ley № $20.066^{5}$, desarrollaremos brevemente las principales características del primer esfuerzo normativo para entender mejor aquellos problemas que la nueva ley trata de superar.

Hoy podríamos caracterizar la Ley № 19.325 como una especie de esfuerzo "terapéutico", cimentado bajo la premisa de la búsqueda de la reconciliación y la reparación de los vínculos familiares afectados por la violencia a través de la intervención judicial, que no cuestionó los elementos ideológicos y las relaciones desiguales que subyacen a la violencia en el espacio íntimo. Este enfoque normativo no es nuevo en el derecho comparado y, tal como advierte Siegel, los primeros esfuerzos en Estados Unidos por reglamentar la violencia doméstica se realizaron por jueces y asistentes sociales que propiciaron por vías formales e informales la preservación de la unificación familiar ${ }^{6}$.

El modelo chileno estableció tres tipos de sanciones: la pena privativa de libertad de hasta 61 días de presidio, la multa y la asistencia obligatoria a programas de asistencia terapéutica. Sin embargo, la forma de término más común de los casos denunciados era un avenimiento propiciado a través de la conciliación judicial. Las cifras oficiales muestran que más del $75 \%$ de los casos terminaban por esa vía. Desde temprano, las evaluaciones a la ley de violencia mostraron que los esfuerzos de los operadores estuvieron guiados por el "proceso de reconciliación" y la preservación de la armonía familiar, teniendo como fundamento los términos de la discusión legislativa.

La ley contempló el Ilamado a conciliación obligatoria que hacía el juez bajo la premisa de la unificación familiar sin que se considerara el riesgo a la integridad física y psíquica de las personas sometidas a violencia; en materia sustantiva las sanciones aplicables eran de escasa eficacia; de hecho el juez no podía ordenar el abandono definitivo del agresor del hogar común. Si lo hacía era una medida temporal que no podía exceder los 180 días.

En el campo de las sanciones, la ley claramente mostró su ineficacia. La principal forma de sanción, establecida en el artículo 4.1 fue la obligación del agresor de concurrir a terapia o un tratamiento de rehabilitación, que en todo caso no podría exceder a seis meses. Escapa a los límites de un comentario legislativo analizar si la aproximación de rehabilitación psicológica acaso no refuerza la idea del hombre con "problemas" y que por ello maltrata y no logra identificar la centralidad de la violencia como una cuestión de subordinación y dominación. Todo ello sin descontar los problemas prácticos de no contar con una red de asistencia de salud mental en el país que pudiera hacer frente efectivamente a esta nueva demanda ${ }^{7}$.

Los casos de violencia intrafamiliar son una de las materias más numerosas en la justicia de familia. Actualmente las cifras muestran que hay más de 
76 mil denuncias por violencia intrafamiliar hasta noviembre de $2005^{8}$, de allí que cualquier modificación a la ley tiene un gran impacto en el funcionamiento de los tribunales y como veremos tiene un efecto aún no previsto en el sistema de justicia penal.

\section{Propósito de la modificación}

Las diputadas Muñoz y Saa, quienes promovieron la Ley № 19.325, cinco años después instaban a su modificación. Finalmente el Ejecutivo, por iniciativa del Servicio Nacional de la Mujer, presentó una indicación sustitutiva en agosto de 2001 que buscó reformular este cuerpo legal e insertarlo dentro de la reforma a la justicia de familia que se discutía de manera coetánea. Esto solucionaba un problema de la antigua ley que entregaba la competencia de estos casos a tribunales civiles. La Ley № 20.066 se promulgó en septiembre del $2005^{9}$ y entró en vigencia el 15 de octubre de ese año, al mismo tiempo que entraban en operación los tribunales de familia.

La ley precisa el concepto de violencia intrafamiliar que consiste en todo maltrato que afecte la vida o la integridad física o psíquica de un miembro de la familia sobre otro ${ }^{10}$. Así, no sólo serán materia de sanción todas aquellas acciones que irroguen lesión a la integridad física, sino también las acciones u omisiones que signifiquen un daño a la integridad psíquica de las personas.

Los elementos que configuran la violencia intrafamiliar están dados por los sujetos que están involucrados. De esta manera, la ley considera la existencia de violencia intrafamiliar cuando el maltrato se produce entre personas unidas o que hubieren estado unidas por matrimonio ${ }^{11}$, en una relación de convivencia, o sin que exista convivencia tengan hijos en común. Esto último es una novedad. También se incluyen como sujetos activos o pasivos a los parientes por consanguinidad o afinidad en toda la línea recta o en la colateral hasta el tercer grado inclusive del ofensor, de su cónyuge o de su actual conviviente y como sujeto pasivo especial el menor de edad o persona con discapacidad que se encuentre bajo el cuidado o dependencia de cualquiera de los integrantes del grupo familiar, sin que sea un pariente de los señalados anteriormente ${ }^{12}$.

Este cuerpo legal obliga a los jueces a realizar una evaluación de riesgos cuando da curso a la tramitación de la demanda, de tal manera que, existiendo peligro de nuevos incidentes de violencia o daño a las víctimas o sus bienes, el tribunal deberá adoptar medidas concretas para su protección ${ }^{13}$. Lo interesante es que la ley le brinda un marco referencial para presumir el riesgo inminente, que existiría en aquellos casos que hayan sido precedidos por la amenaza de causar daño y concurran, además, una o más denuncias previas por violencia intrafamiliar, antecedentes por alcoholismo o drogadicción, condenas previas por violencia o procesos pendientes o condenas por crimen o simple delito en contra de las personas y por algunos de los delitos establecidos en los párrafos 5 y 6 de la Ley № 17.798 sobre control de armas y explosivos. Así la ley impone un conjunto de reglas concretas que deben ser
8 La Tercera, "Denuncias por violencia intrafamiliar superan las 76 mil este año", 21 de noviembre de 2005.

9 Promulgada el 22 de septiembre de 2005, publicada en el Diario Oficial el 7 de octubre de 2005.

10 Artículo 5 de Ley 20.066 .

11 Cónyuge y excónyuge.

12 Inciso $2^{\circ}$ artículo 51 de Ley № 20.066 .

13 Artículo 7 de Ley № 20.066 . 
14 Esta unidad varía su valor mes a mes, y su equivalente en abril de 2006 ascendía a $\$ 31.413$.

15 Artículo 8 inciso $3^{\circ}$ de la Ley № 20.066 .

16 Ultimo inciso del artículo 9 de la Ley № 20.066 .

17 Mera, Alejandra, Delito de Violencia Intrafamiliar. Los problemas de apelar indiscriminadamente a la solución penal, Informe de Investigación, Centro de Investigaciones Jurídicas, Universidad Diego Portales, Santiago, 2004. cumplidas por los jueces al admitir los casos a tramitación, sin esperar para ello el término de la tramitación de la causa, evitando de esta manera discrecionalidad judicial que pueda ir en perjuicio de las víctimas.

Si la principal sanción de la antigua ley fue la "medida terapéutica", la Ley № 20.066 se centra en la imposición de la multa que, atendida la gravedad del acto, oscilará entre media a 15 unidades tributarias mensuales $(\mathrm{UTM})^{14}$. A diferencia de la Ley № 19.325 en que la multa era recaudada a beneficio fiscal, ahora está destinada a beneficio de los gobiernos regionales del domicilio del denunciante o demandante con el objeto de apoyar los centros de atención de víctimas de violencia intrafamiliar, sean estos de financiamiento público o privado ${ }^{15}$.

Además de la multa, el artículo 9 de la ley dispone que el juez deberá ordenar medidas accesorias consistentes en la obligación del ofensor de abandonar el hogar común, la prohibición de acercarse a la víctima, a su domicilio, lugar de estudio o trabajo; la prohibición de porte o tenencia de armas de fuego o decomiso de éstas, y la obligación de asistir a programas terapéuticos o de orientación familiar. Estas medidas no pueden ser impuestas por menos de seis meses y no podrán exceder de un año. Sin embargo, podrán ser renovadas, a petición de la víctima, si las circunstancias que dieron lugar a ellas se mantienen. Si bien se podría argumentar que esto no es muy distinto de la antigua ley, la existencia de una ley de divorcio ayuda a que los jueces puedan ordenar la salida permanente del hogar común.

Otra novedad es que el juez también establecerá la obligación de pagar los desembolsos y perjuicios patrimoniales que el acto del ofensor haya causado. Ello incluye la reposición en dinero o en especie de bienes dañados, destruidos o perdidos, lo que será avaluado prudencialmente por el juez.

A su vez, la ley dispone que el juez en la sentencia definitiva por violencia deberá fijar los alimentos definitivos y el régimen de cuidado y de relación directa y regular con los hijos, a fin de normar las situaciones conexas que pueden significar más puntos de conflicto y violencia entre las partes y el resto del grupo familiar ${ }^{16}$.

Una de las cuestiones aplaudidas por el movimiento de mujeres y criticada desde la academia es el potencial uso indiscriminado de la herramienta penal ${ }^{17}$. Esta ley tipifica el delito de maltrato habitual, el que en todo caso será determinado por un juez de familia, después de lo cual derivará la materia para conocimiento en sede penal. El delito consiste en la habitualidad de la conducta -maltratar física o síquicamente a cualquiera persona de las enumeradas en el artículo 5 de la Ley-y especifica aquellos elementos necesarios para configurarla. Para ello considerará el número de actos ejecutados y la proximidad de los mismos, independientemente de si los actos de violencia sean ejecutados en contra de la misma víctima o de otra persona. Aun cuando la ley no lo expresa, la redacción -y sus efectos prácticos- sugerirían que para calificar la habitualidad del maltrato, este debiera estar dirigido a víctimas en el mismo entorno 
familiar, así el entorno sería el dañado. De otra manera, no se entendería cuál es el sentido de la disposición. Aún así, esto no lograría satisfacer el principio de legalidad como lo sugiere Mera ${ }^{18}$, pues no es claro cómo se satisfacen en concreto los contornos de la conducta que va a merecer un reproche penal ni si los actos de violencia deben estar unidos por algún elemento en común de temporalidad y causa.

Creemos que será de relevancia la creación de estándares judiciales que deslinden el contenido normativo de habitualidad, cuestión que, como sugiero, queda en manos de los tribunales de familia, pero cuyo test definitivo pueda quedar en los tribunales penales.

La ley especifica que no podrán ser considerados para efectos de determinar la habitualidad hechos anteriores respecto de los cuales se hubiera dictado sentencia condenatoria o absolutoria ${ }^{19}$. Se dispone, además, que para los casos de violencia no procederá el acuerdo reparatorio entre víctima e imputado ${ }^{20}$. Ahora, es posible que las situaciones de violencia entren directamente al sistema por lesiones en el marco de violencia intrafamiliar. En este caso, las lesiones siguen un régimen común y pueden ser objeto de acuerdos reparatorios entre víctima e imputado. Esta situación pudiera variar si el Ministerio Público promoviera una política criminal concordante con los principios que orientan el nuevo tratamiento de la violencia intrafamiliar y no permitiera esta salida. Ello podría plantear problemas del establecimiento de un tratamiento desigual para similares situaciones. Nuevamente, esta será una cuestión que se dilucidará a través de los estándares y la interpretación que los operadores le den a esta normativa.

La ley deja a salvo la posibilidad de aplicar la suspensión condicional del procedimiento en sede penal, para lo cual el juez de garantía impondrá como condición una o más de las medidas establecidas en el artículo 9 de la Ley № 20.066, sin perjuicio de las establecidas en el artículo 238 del Código Procesal Penal ${ }^{21}$.

En conexión a salidas alternativas en materia civil, estas se encuentran establecidas en la ley de tribunales de familia. Esta ley dispone que los casos de violencia podrán ser sometidos a mediación sólo si hay reconocimiento de los hechos fundantes de la demanda o denuncia, si no existen antecedentes previos de violencia en contra del demandado o denunciado independiente de la víctima o condena por algún crimen o simple delito contra las personas, delitos sexuales, o cuando el juez estime conveniente la continuación del proceso ${ }^{22}$. También puede proceder la suspensión de dictación de sentencia siempre y cuando el denunciado reconozca los hechos fundantes de la demanda o denuncia y se comprometa a observar las condiciones que imponga el juez $z^{23}$.

Los procesos por conflictos familiares hacen que el tema de la mediación y violencia sean adecuadamente entendidos por todos los operadores. Tendrá que existir un especial cuidado en los casos de violencia, a fin de asegurar que las partes se encuentren efectivamente en iguales condiciones de negociar. En la medida de que hay una subordinación y
18 Ibid., p. 32.

${ }^{19}$ Inciso $2^{\circ}$, artículo 14 de la Ley № 20.066 .

20 Artículo 19 de la Ley № 20.066 .

21 Artículo 17 de la Ley № 20.066.

22 Artículo 104 inciso $2^{\circ}$ de la Ley № 19.968 publicada en el Diario Oficial 30 de agosto de 2004.

23 Artículo 96 de la Ley № 19.968 . 
24 Artículo 3 de la Ley № 20.066 . sumisión relevante, ello no permitirá que una de las partes pueda adoptar acuerdos sin estar sometida a coacción. Por otra parte, tanto jueces como mediadores debieran advertir que la mediación de materias conexas a la ruptura de una pareja en el contexto de violencia tales como los alimentos, la regulación de régimen de visitas o el cuidado de los hijos, puede ser igualmente problemática por la asimetría en la relación. Esta precaución implica deberes éticos de suspender este proceso cuando las condiciones sólo reafirmen desigualadad y sumisión.

\section{Los desafíos de esta ley}

La Ley № 20.066 plantea una serie de desafíos. Tal como sugieren aquellos sectores que trabajan directamente con mujeres víctimas, el enfoque de la ley continúa centrándose en "la violencia intrafamiliar", lo cual desperfila los elementos de género que subyacen a esta.

Aquellos operadores que deben aplicar la nueva normativa deben contar con las herramientas y formación suficientes, cuestión que se declara en la ley ${ }^{24}$. Más allá de este acto de buena voluntad, la adopción de este cuerpo legal no contempló la existencia de una partida presupuestaria para el desarrollo de recursos humanos especializados para aquellas instituciones que tendrán una mayor carga de trabajo y que no han tenido una política definida en la materia, como el Ministerio Público. De esta manera, aventurarse a exigir la aplicación de sanciones penales sin que exista capacitación a jueces, defensores y fiscales sobre violencia, puede minar la legitimidad del sistema, si la aplicación de las normas resulta deficiente o problemática para la protección de las víctimas. 